\title{
Experimental Investigation of PCC Incorporating RAP
}

\author{
Sawssen El Euch Ben Said ${ }^{1)}$, Saloua El Euch Khay²), and Amara Loulizi' ${ }^{2), *}$ (1)
}

(Received January 19, 2016, Accepted October 31, 2017)

\begin{abstract}
Rehabilitation and repair of flexible pavements produce huge amounts of reclaimed asphalt pavement (RAP) material. Using RAP in the formulation of portland cement concrete (PCC) is a technique that is part of a sustainable development approach since it reduces on the consumption of new aggregates and reuses a material that is considered as waste. This paper describes the semi-adiabatic calorimetry test performed on a concrete mix incorporating RAP material as aggregate. Results showed that the cement hydration process is not affected by the presence of asphalt coated on the surface of RAP material. Classical tests (compressive strength, flexural and indirect-tensile strengths, elastic modulus, and free-shrinkage) were also performed on PCC mixes incorporating different percentages of RAP. It was found that as the percentage of RAP increases, the PCC mechanical properties decrease. This is mainly attributed to the presence of voids in the transition zone between the asphalt-coated aggregates and the hydrated cement paste as confirmed by scanning-electron microscope images. Unrestrained shrinkage testing showed statistically insignificant change in shrinkage strain with RAP content. The strength and shrinkage results lead to conclude that as much as $40 \%$ of RAP could be incorporated into the formulation of PCC and achieve properties that are acceptable for the construction of rigid pavements.
\end{abstract}

Keywords: portland cement, recycled asphalt pavement, heat of hydration, semi-adiabatic, shrinkage, rigid pavements, sustainability.

\section{Introduction}

The incorporation of recycled aggregates, obtained from the rehabilitation and demolition of old infrastructure (buildings, pavements, and bridges), into the formulation of PCC has become an essential practice for sustainable development. Several studies around the world have been particularly interested in the use of recycled concrete aggregates (RCA) (Choi et al. 2016; Yehia et al. 2015; McNeil and Kang 2013) and RAP (Okafor 2010; Kolias 1996; El Euch Ben Saïd et al. 2014; Roberts et al. 1996; Sommer 1994; Topcu and Isikdag 2009; Delwar et al. 1997; Huang et al. 2006; Hossiney et al. 2010; Brand and Al-Qadi 2012; Li et al. 1998; Hassan et al. 2000; Al-Oraimi et al. 2009; Mahmoud et al. 2013; Bermel 2011; Mathias et al. 2004; Abdel-Mohti et al. 2016; Hossiney et al. 2010; Brito and Saikia 2013) for the production of new PCC. In fact,

\footnotetext{
${ }^{1)}$ LR11ES16 Laboratory of Materials, Optimization, and Environment for Sustainability, Higher Institute of Technological Studies at Rades, B.P. 37 Le Belvédère, 1002 Tunis, Tunisia.

${ }^{2)}$ LR11ES16 Laboratory of Materials, Optimization, and Environment for Sustainability, National Engineering School of Tunis, Tunis El Manar University, B.P. 37 Le Belvédère, 1002 Tunis, Tunisia.

*Corresponding Author; E-mail: amlouliz@vt.edu Copyright (c) The Author(s) 2018. This article is an open access publication
}

using RCA and RAP material in the formulation of PCC permits not only to value a material that is considered as solid waste in many parts of the world, but also to limit the usage of quarry products leading to preserving natural aggregate resources and energy. For example, it is estimated that the embodied energy (defined as the total energy required to produce and install a material during all stages of the life cycle) and the embodied carbon (defined as the quantity of released $\mathrm{CO}_{2}$ during a material's life cycle) of limestone aggregates are $250 \mathrm{MJ} \mathrm{t}^{-1}$ and $12 \mathrm{~kg} \mathrm{t}^{-1}$, respectively (Calkins 2009). Therefore, replacing limestone aggregates with RAP would reduce the embodied energy and carbon of the formulated PCC. Moreover, depletion of materials in existing quarries and difficulties in opening new ones, given the limited availability of natural deposits, impose researchers in the area of construction materials to find new sources of supply. In this context and in order to minimize the use of natural aggregate resources in the country, several studies in Tunisia have focused on using abundant local materials in the road sector. For instance, dune sand, crushed quarry sand, and sea-dredged sediments were incorporated in the formulation of sand concrete (El Euch Khay et al. 2010a, b, 2011; Ben Othmen et al. 2013) and RAP material were tested for usage in the formulation of cement-treated aggregates (El Euch Ben Saïd et al. 2014) and PCC (object of this paper). 


\section{Research Background}

Because of repair, rehabilitation, and reconstruction of deteriorated pavements with hot-mix asphalt wearing surfaces, a large amount of RAP material is generated annually from the milling process. Since stocks of RAP have negative effects on the environment, several studies were undergone to reuse this material in new construction projects, mainly in the formulation of new hot-mix asphalt (Roberts et al. 1996).

Another possible use of RAP, especially in countries with no or little resources of asphalt and good provisions of portland cement, is in the formulation of PCC. Several research efforts have focused on studying the influence of the introduction of RAP on the mechanical resistance of PCC: compressive, flexural, and indirect tensile strengths (Okafor 2010; Kolias 1996; Sommer 1994; Delwar et al. 1997; Huang et al. 2006; Hossiney et al. 2010; Brand and Al-Qadi 2012; Li et al. 1998; Hassan et al. 2000; Al-Oraimi et al. 2009; Mahmoud et al. 2013; Bermel 2011; Mathias et al. 2004; Abdel-Mohti et al. 2016). All published results assert that the strength of PCC decreases with an increase in the incorporated percentage of RAP, but with no thorough explanation of the reasons behind this decrease. The same trend was also found for the PCC elastic modulus (Sommer 1994; Delwar et al. 1997; Huang et al. 2006; Hossiney et al. 2010; Brand and Al-Qadi 2012; Al-Oraimi et al. 2009; Mahmoud et al. 2013; Mathias et al. 2004). On the other hand, results on the effects of RAP on PCC free shrinkage are controversial. In fact, some researchers claim that the incorporation of RAP has no effect on PCC shrinkage behaviour (Sommer 1994; Brand and Al-Qadi 2012), others claim that RAP tends to reduce shrinkage of PCC (Hossiney et al. 2010), another group reported inconclusive results (Hossiney et al. 2010), and some researchers found that RAP increases shrinkage of PCC (Abdel-Mohti et al. 2016; Brito and Saikia 2013). In addition, a small number of researchers investigated whether the fine or coarse portion of RAP has more negative effects on PCC strength properties. Results on this context were also discordant; with a study showing that replacing only the coarse portion has less negative effect than replacing both portions (coarse and fine) (Hassan et al. 2000), while another study claims that replacing the fine portion with its equivalent RAP material results in better PCC mixes (Huang et al. 2006).

The originality of the work described in this paper is the study of the hydration kinetics of PCC containing RAP. In fact, to the authors' best knowledge, no research team evaluated the influence of asphalt present in RAP on the cement hydration process. For that purpose, semi-adiabatic calorimetry tests were performed. In addition, PCC incorporating local materials and different percentages of RAP were tested to validate the use of such material in the construction of rigid pavements.

\section{Materials}

All PCC mixes made for this study were composed of local materials (RAP, fine and coarse aggregates, portland cement, and water) with no mineral or chemical admixtures. Portland cement from a local plant was used and is classified as CEM I-42.5 according to Tunisia specification NT-47.01 (INORPI 1996). This cement has a specified 28-day compressive strength of $40 \mathrm{MPa}$, a specified 2-day compressive strength of $10 \mathrm{MPa}$, and a specific gravity of 3.10 . According to its manufacturer, the percentages per mass of its main constituents are: $54.4 \%$ of tricalcium silicates $(\mathrm{C} 3 \mathrm{~S})$, $18.6 \%$ of dicalcium silicates $(\mathrm{C} 2 \mathrm{~S}), 11.4 \%$ of tricalcium aluminates (C3A), and $9 \%$ of tetracalcium aluminoferrite (C4AF). The new aggregates (fine and coarse) were obtained from a local limestone quarry, while potable water was used for mixing. A 20-mm maximum aggregate size was used for all produced mixes. RAP material was obtained from the milling process of a national highway. The pavement was 14-years old prior to milling; the asphalt content of the material, as obtained from extraction tests, was about 5\%; while the penetration grade of the asphalt was $35 / 50$. The RAP material was used in its milled state with no processing (fracture of particles or taking out of binder) performed. To study the effects of RAP gradation on PCC performance, three different size classes of RAP were used: 0/20, 0/4 (fine portion) and $4 / 20$ (coarse portion). The coarse and fine portion of the RAP were obtained after careful sieving through a $4 \mathrm{~mm}$ sieve of the $0 / 20$ RAP. The gradation notation $d / D$ means that at least $95 \%$ of the material passes the $\mathrm{D}$ sieve and is retained in the $\mathrm{d}$ sieve $(\mathrm{d}$ and $\mathrm{D}$ are expressed in $\mathrm{mm}$ ). The gradations of the three classes of RAP are shown in Fig. 1. The main properties of RAP, fine and coarse aggregates were studied and are displayed in Table 1 .

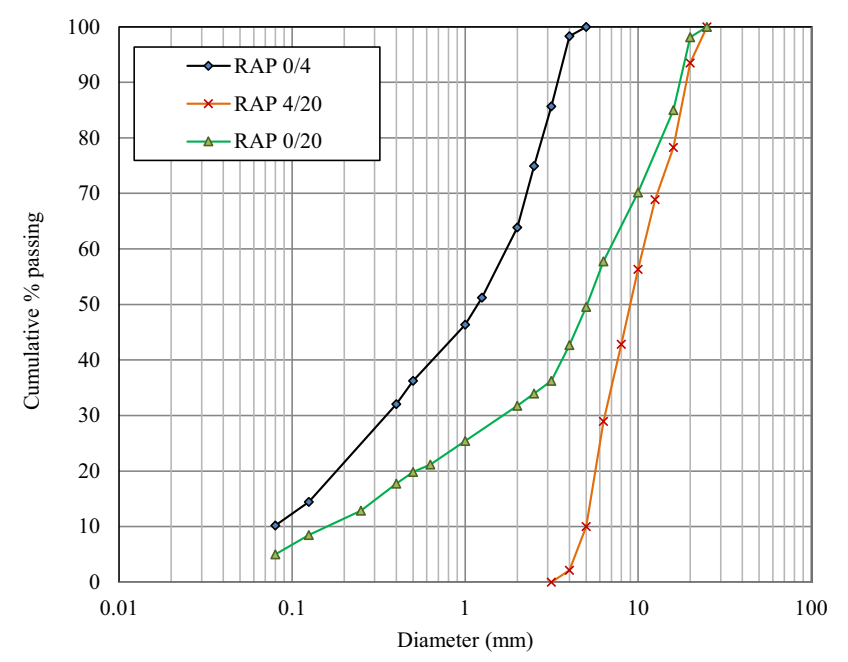

Fig. 1 Gradation curves of used RAP. 
Table 1 Properties of RAP, fine and coarse aggregates.

\begin{tabular}{c|c|c|c}
\hline & RAP & Coarse aggregates & Fine aggregates \\
\hline \hline Dry specific gravity & 2.36 & 2.52 & 2.56 \\
\hline$\%$ filler $(<80 \mathrm{~m})$ & 8.5 & 0.8 & 12 \\
\hline Absorption capacity (\%) & 0.7 & 1.5 & 0.9 \\
\hline
\end{tabular}

\section{Laboratory Testing Program}

The laboratory experimental program had three major objectives: to examine whether or not asphalt, coated on RAP, affects PCC hydration process, to quantify the effect of RAP content on mechanical and shrinkage properties of PCC, and to determine, for the same RAP content, which replaced portion (fine or coarse) has more negative effects on PCC properties. Once the second objective is achieved, it is easy to define the threshold RAP content under which PCC containing RAP can be used for constructing rigid pavements. A 28-day compressive strength of $20 \mathrm{MPa}$ and an indirect tensile strength of $2 \mathrm{MPa}$, as suggested by the French specification, NFP 98-170, for constructing rigid pavements for class 2 concrete (AFNOR 1992), were used in this study to find the threshold RAP content. Figure 2 shows the performed tests on all the mixes: semi-adiabatic calorimetry, compressive strength test with its initial low-stress portion used to calculate the elastic modulus, the indirect tensile strength test, the 3-point bending test, and the free-shrinkage test.

The tests of compressive and indirect tensile strengths were performed on cylindrical specimens $16 \mathrm{~cm}$ in diameter by $32 \mathrm{~cm}$ in length, while the 3-point bending and free-shrinkage tests were performed on prismatic beams $7 \mathrm{~cm} \times 7 \mathrm{~cm} \times$ $28 \mathrm{~cm}$ in dimension. Since shrinkage of concrete is significantly affected by the conditions before and after setting, all specimens were prepared and kept, once the moulds were removed, in standard conditions (ambient temperature of $20 \pm 2{ }^{\circ} \mathrm{C}$ and relative humidity of $50 \pm 2 \%$ ). Length measurements were performed by means of a retractometer equipped with a dial gauge that has a sensitivity of $1 \mathrm{~m}$. For each mix and for each test, three specimens were evaluated.

In total eight PCC mixes were prepared for this study. The mixes were labelled as F (for formula) followed by a number
$(0,20,40,60,80$, and 100) that represents the used percentage of $0 / 20 \mathrm{RAP}$ in the mix. These percentages represent the volume of used RAP with respect to the total volume of aggregates (fine and coarse). Mix F0 composed of 100\% new aggregates served as a control mix. Another letter ( $\mathrm{S}$ or G) was added after the number for two mixes (F40S and F40G) to specify whether the used RAP is graded as $0 / 4$ (S for sand) or $4 / 20$ ( $\mathrm{G}$ for gravel). All mixes were designed based on the granular packing model as proposed by De Larrard (1999). The final proportioning of all mixes made for this study, is shown in Table 2. For all mixes, the cement content was kept constant at $330 \mathrm{~kg} \mathrm{~m}^{-3}$ (a typical cement content for concrete used in the construction of rigid pavements) and the w/c ratio was kept at 0.6. The slump of the achieved mixes was between $5 \mathrm{~cm}$ to $6 \mathrm{~cm}$, indicating a plastic concrete that could be placed using conventional slipform paving techniques. The laboratory tests were carried out on all studied mixes (a total of eight as shown by Table 1) with the exception of the semi-adiabatic calorimetry test where only the two extreme formulations were examined (F0 and F100). Three replicates were evaluated at each testing date for all tests and for all mixes.

\section{Semi-adiabatic Calorimetry Testing}

In order to verify if asphalt, coated on RAP, affects or not PCC hydration process, semi-adiabatic calorimetry testing was performed on two mixes, F0 and F100. It is a known fact that the chemical reactions involved in portland cement hydration are all exothermic; that is they liberate heat. The heat of hydration depends on the cement type and the w/c ratio. Since mixes F0 and F100 have the same cement type and $\mathrm{w} / \mathrm{c}$ ratio, it is expected that they liberate the same heat

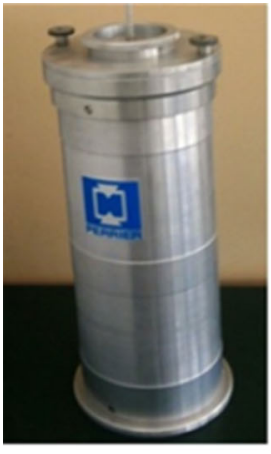

(a)

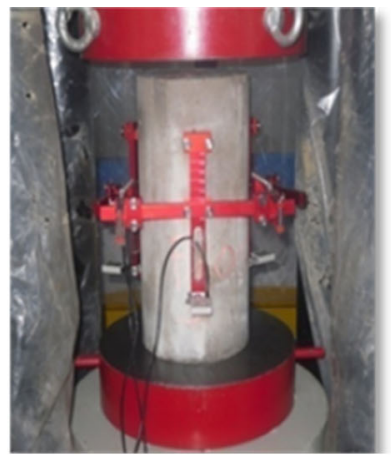

(b)

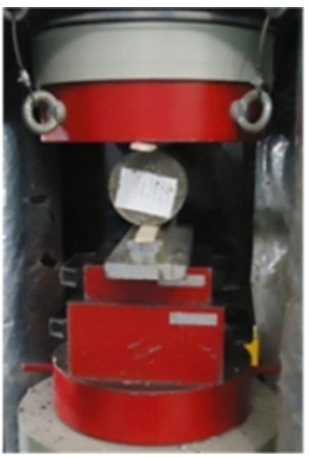

(c)

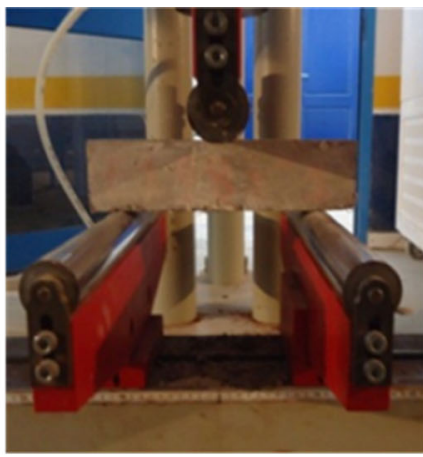

(d)

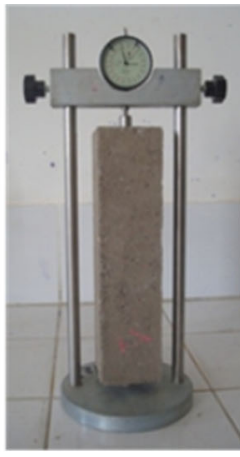

(e)

Fig. 2 Performed laboratory tests: a semi-adiabatic calorimeter device, b compressive strength and elastic modulus, c indirecttensile strength, d 3-point flexural strength, e free-shrinkage. 
Table 2 Proportioning of all studied PCC mixes.

\begin{tabular}{c|c|c|c|c|c|c|c|c}
\hline Mix label & $\begin{array}{c}\text { RAP content } \\
(\%)\end{array}$ & $\begin{array}{c}\text { Water } \\
\left(\mathrm{kg} \mathrm{m}^{-3}\right)\end{array}$ & $\begin{array}{c}\text { Cement } \\
\left(\mathrm{kg} \mathrm{m}^{-3}\right)\end{array}$ & $\begin{array}{c}\text { RAP 0/20 } \\
\left(\mathrm{kg} \mathrm{m}^{-3}\right)\end{array}$ & $\begin{array}{c}\text { RAP 0/4 } \\
\left(\mathrm{kg} \mathrm{m}^{-3}\right)\end{array}$ & $\begin{array}{c}\text { RAP 4/20 } \\
\left(\mathrm{kg} \mathrm{m}^{-3}\right)\end{array}$ & $\begin{array}{c}\text { New gravel } \\
\left(\mathrm{kg} \mathrm{m}^{-3}\right)\end{array}$ & $\begin{array}{c}\text { New sand } \\
\left(\mathrm{kg} \mathrm{m}^{-3}\right)\end{array}$ \\
\hline \hline F0 & 0 & 198 & 330 & 0 & 0 & 0 & 965 & 806 \\
\hline F20 & 20 & 198 & 330 & 328 & 0 & 0 & 772 & 645 \\
\hline F40 & 40 & 198 & 330 & 656 & 0 & 0 & 579 & 484 \\
\hline F60 & 60 & 198 & 330 & 984 & 0 & 0 & 386 & 323 \\
\hline F75 & 75 & 198 & 330 & 1312 & 0 & 0 & 241 & 202 \\
\hline F100 & 100 & 198 & 330 & 1640 & 0 & 0 & 0 \\
\hline F40S & 40 & 198 & 330 & 0 & 656 & 0 & 965 & 102 \\
\hline F40G & 40 & 198 & 330 & 0 & 0 & 656 & 253 & 806 \\
\hline
\end{tabular}

at the same rate during hydration, unless the asphalt present in mix F100 affect this hydration reactions.

The Langavant-type semi-adiabatic calorimeter (shown in Fig. 2a) was used in this study to calculate the heat released from samples taken right after batching F0 and F100 mixes. Each sample was placed inside an $800 \mathrm{~cm}^{3}$ capacity tinplate cylindrical container, which is placed by itself inside the calorimeter. The latter is a silvered Pyrex glass cylindrical container with a hemispherical bottom. For every calorimeter, a thermocouple was placed inside the PCC sample in order to measure temperature development over time. Temperature measurements were taken at successive intervals over a seven-day period. The ambient temperature around the calorimeters was set constant at $20{ }^{\circ} \mathrm{C}$.

The hydration of cement paste in PCC is a thermo-activated process, which development could be modelled using an Arrhenius type equation (Eq. 1) as proposed by Ulm and Coussy (1994).

$\frac{d \xi}{d t}=\tilde{A}(\xi) e^{\left(-\frac{E_{a}}{R \times T}\right)}$

where $\xi$ is the degree of hydration, $\tilde{A}(\xi)$ is the normalized chemical affinity $\left(\mathrm{s}^{-1}\right), E_{a}$ is the activation energy $\left(\mathrm{J} \mathrm{mol}^{-1}\right)$, $\mathrm{R}$ is the perfect gas constant $\left(8.314 \mathrm{~J} \mathrm{~mol}^{-1} \mathrm{~K}^{-1}\right)$, and $\mathrm{T}$ is the absolute temperature $(\mathrm{K})$. The semi-adiabatic test has been simulated in detail elsewhere (Briaut et al. 2010), therefore, only the key equations needed to interpret the results are presented hereafter. The quantity of heat released during hydration at time $t(Q(t))$ can be written under adiabatic conditions as shown by Eq. 2a, or under semi-adiabatic conditions as shown by Eq. 2 b.

$$
Q(t)=C_{c} \times\left(T_{a d}(t)-T_{c}(0)\right)
$$

$Q(t)=C_{t} \times(\theta(t)-\theta(0))+\int_{0}^{t}(a+b \times \theta(u)) \times \theta(u) \times d u$ where $C_{c}$ is the concrete heat capacity $\left(\mathrm{J} \times{ }^{\circ} \mathrm{C}^{-1}\right), T_{a d}(t)$ is the concrete temperature at time $t$ under adiabatic conditions, $T_{c}(0)$ is the concrete temperature at time 0 under adiabatic conditions, $C_{t}$ is the total heat capacity (concrete plus calorimeter), $\theta(t)$ is the measured concrete temperature at time $t, \theta(0)$ is the measured concrete temperature at time 0 , $a\left(\mathrm{~W} \times{ }^{\circ} \mathrm{C}^{-1}\right)$ and $b\left(\mathrm{~W} \times{ }^{\circ} \mathrm{C}^{-2}\right)$ are the calorimeter heat loss coefficients. The total heat capacity can be calculated as presented by Eq. 3 .

$C_{t}=C_{c}+n=\left(C_{c i} \times m_{c i}+C_{a} \times m_{a}+C_{w} \times m_{w}\right)+\mu$

where $C_{c i}, C_{a}$, and $C_{w}$ are the specific heat capacities $\left(\mathrm{J} \times \mathrm{kg}^{-1} \times{ }^{\circ} \mathrm{C}^{-1}\right)$ of cement, aggregates, and water, respectively; $m_{c i}, m_{a}$, and $m_{w}$ are the mass $(\mathrm{kg})$ of cement, aggregates, and water, respectively, and $\mu$ is the heat capacity of the calorimeter.

From the mix design and the reported calorimeter property $(\mu), C_{t}$ could be easily calculated using Eq. 3 . Then, using the measured concrete temperature during the test, the quantity of heat released during hydration could be easily calculated using Eq. 2b. Once $Q(t)$ is determined, the temperature under adiabatic condition could be deduced from Eq. $2 \mathrm{a}$ as shown by Eq. 4 .

$T_{a d}(t)=\frac{Q(t)}{C_{c}}+T_{c}(0)$

The degree of hydration as a function of time could, then, be calculated from the adiabatic temperature as shown by Eq. 5.

$\xi(t)=\xi_{\infty} \times \frac{T_{a d}(t)-T_{c}(0)}{T_{\infty}^{a d}-T_{0}^{a d}}$

where $\xi_{\infty}$ is calculated using model proposed by Waller (2000), shown by Eq. 6 . 


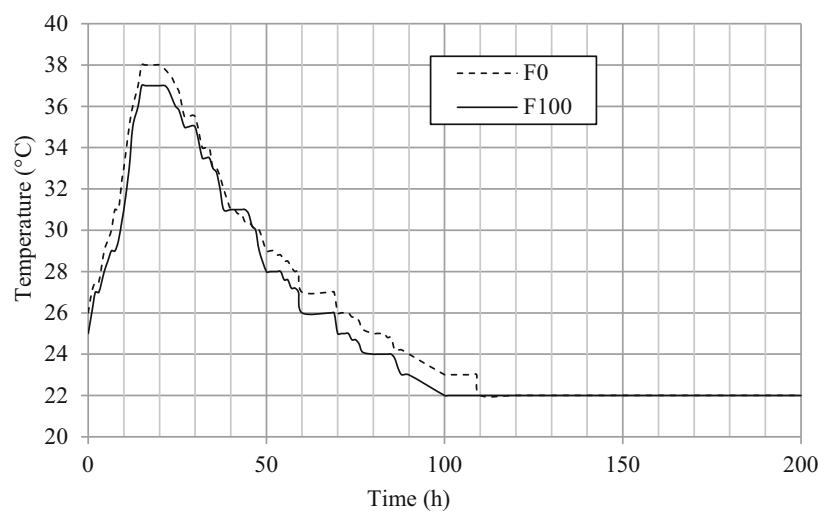

Fig. 3 Temperature development inside PCC specimens of mixes $\mathrm{F} 0$ and F100.

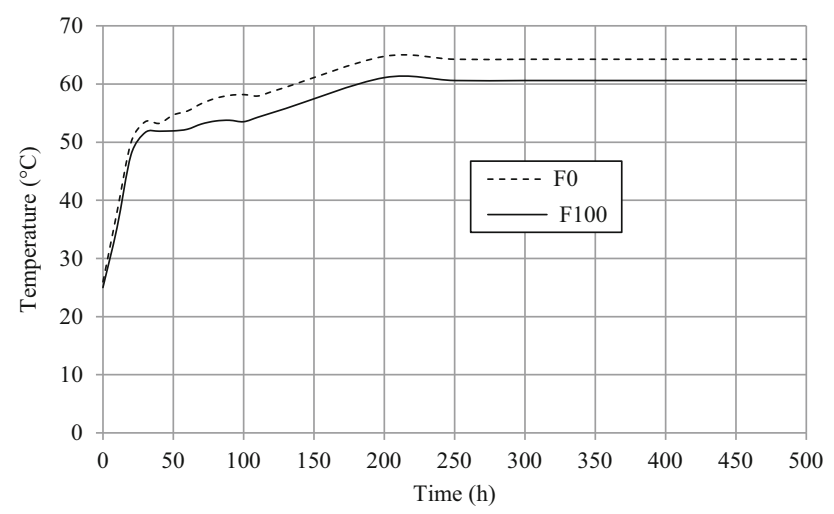

Fig. 4 Adiabatic temperature development for mixes F0 and F100.

$\xi_{\infty}=1-e^{\left(-3.33 \times \frac{w}{c}\right)}$

Figure 3 shows the measured concrete temperature as a function of time for both mixes, F0 and F100. The figure shows that the maximum temperature was reached at about the same time $(15 \mathrm{~h})$ for both mixes. For mix F0, the maximum reached temperature was $38{ }^{\circ} \mathrm{C}$, while that of mix F100 was $37{ }^{\circ} \mathrm{C}$. After about $110 \mathrm{~h}$, the temperature stabilized at about $22{ }^{\circ} \mathrm{C}$ for both mixes. Figure 4 shows the calculated adiabatic temperature for both mixes. The

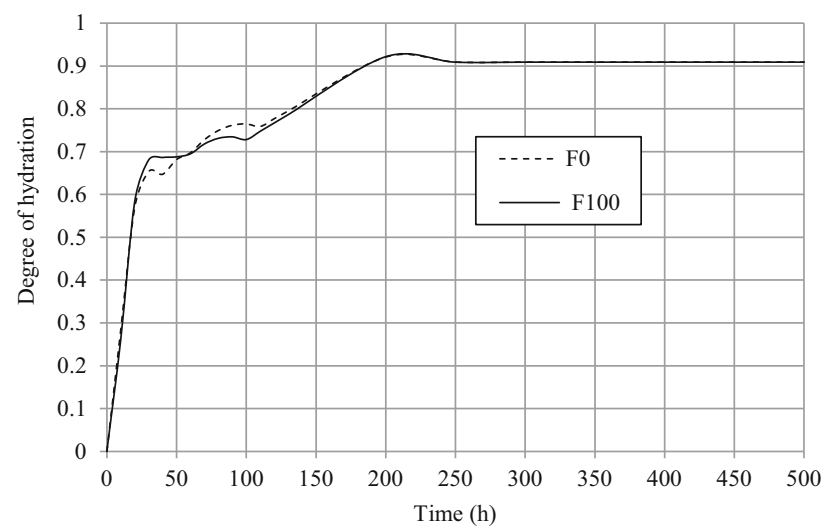

Fig. 5 Degree of hydration development for mixes F0 and F100. adiabatic temperature stabilized at 65 and $61{ }^{\circ} \mathrm{C}$ For mixes F0, and F100, respectively. Figure 5 shows the degree of hydration development for both mixes. The curves follow the exact same trend, which indicates that the hydration process is similar for both mixes. These results prove that asphalt, coated on RAP, does not alter the cement paste hydration process and therefore PCC incorporating RAP could be used for the construction of rigid pavement if its mechanical and shrinkage properties are adequate for such application. These properties were therefore tested in the lab and the results are presented hereafter.

\section{Effect of RAP Content on Properties of PCC}

In order to quantify the effect of RAP content on PCC properties, mixes F0, F20, F40, F60, F80, and F100 were tested for their compressive strength, indirect tensile and flexural strengths, modulus of elasticity, and free shrinkage behaviour.

\subsection{Testing Results}

Figure 6 shows the results of the compressive strength as well as density for all tested mixes at 7,14 , and 28 days of age. It is noted that both properties decrease as RAP content increases. For all tested mixes, the compressive strength after 7 days of age is approximately equal to $75 \%$ of that reached after 28 days. The average 28-day compressive strength of the control mix is $30.1 \mathrm{MPa}$, while that of F100 is $11.4 \mathrm{MPa}$, representing a decrease of about $62 \%$. It is also noticed that only mixes F0, F20 and F40 reached the 20-MPa required compressive strength for concrete to be used in the construction of rigid pavement.

The 28-day indirect tensile and flexural strength results are shown in Fig. 7. These two properties also decrease as the RAP content increases. However, the decrease is not as pronounced as that for compressive strength. In fact, the average indirect tensile strength of mix F0 is $3.1 \mathrm{MPa}$ and that for F100 is $1.7 \mathrm{MPa}$, representing a decrease of about $45 \%$. Also, the average flexural strength of mix F0 is $4.8 \mathrm{MPa}$, while that of mix F100 is $2.5 \mathrm{MPa}$, representing a decrease of about $48 \%$. For all tested mixes, the indirect tensile strength and the flexural strength represent about $10-15$ and $16-22 \%$ of the average 28 -day compressive strength, respectively. In addition, except for mix F100, the 28-day indirect tensile strength of $2 \mathrm{MPa}$ was achieved by all the mixes.

Figure 8 shows the results of the calculated modulus of elasticity, which is a fundamental pavement design parameter. The modulus is calculated using the slope of the secant line at about $40 \%$ of the ultimate strength (secant modulus of elasticity). The elastic modulus decreased from a value of 31 GPa for mix F0 to only $14.5 \mathrm{GPa}$ for mix F100. This means that the introduction of RAP in PCC reduces its rigidity, which is an interesting result for pavement design purposes as will be explained hereafter. 


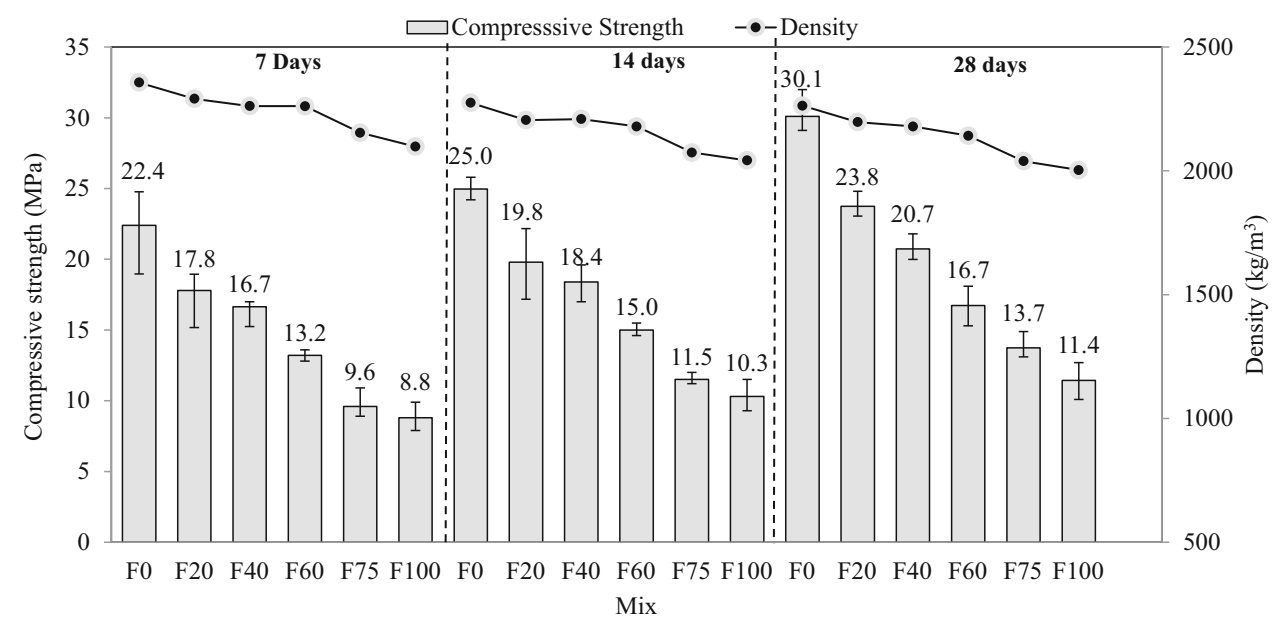

Fig. 6 Compressive strength and density of mixes F0 through F100.

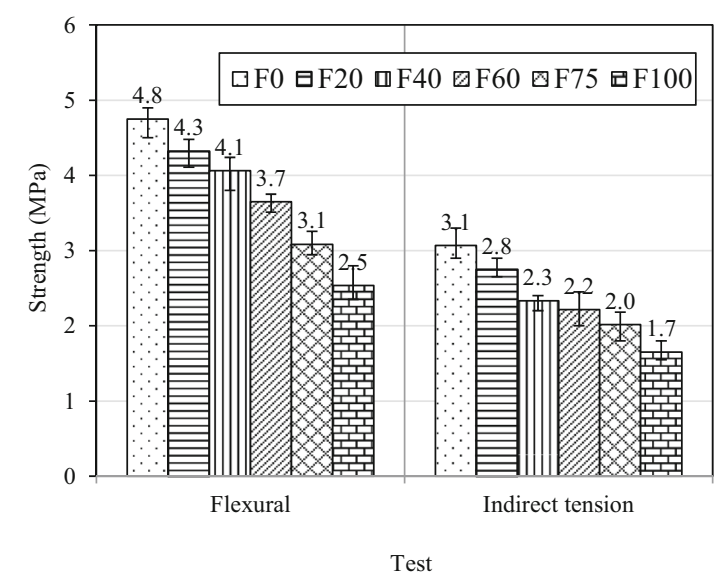

Fig. 7 28-Day indirect tensile and flexural strength results for mixes F0 through F100.

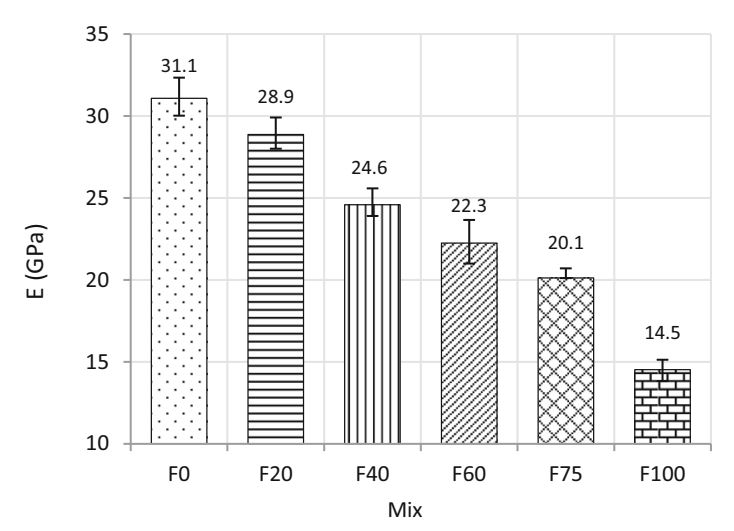

Fig. 8 Calculated modulus of elasticity for mixes F0 through F100.

Figure 9 shows the average shrinkage strain development over time for all tested mixes. It is clear that all curves follow the same trend, indicating that RAP does not have a significant effect on this property. The average 90-day shrinkage strain did not exceed a value of $420 \mu \mathrm{m} \mathrm{m}^{-1}$ for all mixes. Mix F100 showed the largest average strain, $418 \mu \mathrm{m} \mathrm{m}^{-1}$, after 90 days of age, which is higher by only $13 \%$ with respect to mix F0 that exhibited the lowest average shrinkage strain, $370 \mu \mathrm{m} \mathrm{m}^{-1}$, during the same period.

\subsection{Results' Interpretation}

Figure 10 shows the variations of the different studied PCC mechanical resistances as a function of RAP content. The figure shows also the exponential regression curves that fit the data. For the compressive strength data, an exponential regression curve fits much better the measurements than a linear line in terms of the coefficient of determination (0.996 vs. 0.979$)$ and mainly the standard error (0.7 MPa vs. 1.6 MPa). For the indirect tensile strength and flexural strength, the exponential regression is not very different from the linear one, but the former was selected to keep the same type of equation for all properties. The incorporation of RAP into PCC leads to a drop of the compressive strength, indirect tensile strength, and flexural strength as shown by Eqs. 7, 8, and 9, respectively.

$f_{c}^{\prime}=f_{c 0}^{\prime} \times e^{-0.01 \times \% R A P}$

$T=T_{0} \times e^{-0.006 \times \% R A P}$

$R=R_{0} \times e^{-0.006 \times \% R A P}$

where $f_{c}^{\prime}(T$ or $R)$ is the 28-day compressive strength of the mix (indirect tensile strength or flexural strength), $f_{c 0}^{\prime}\left(R_{0}\right.$ or $T_{0}$ ) is the 28-day compressive (indirect tensile strength or flexural strength) of the mix with zero RAP content, and \%RAP is the percentage RAP in the mix. This finding is expected since the presence of asphalt on the surface area of coarse and fine aggregates negatively affects the strength of the interfacial zones contained in hardened PCC and mainly the zone between the cement paste and coarse aggregates and the interfaces between the various phases that make up the cement paste. For instance, the bond strength of the interfacial zone between coarse aggregate and cement paste depends on the former surface characteristics (mainly its roughness) and on chemical bonding depending on the minerals found in the aggregates. In fact, the presence of 


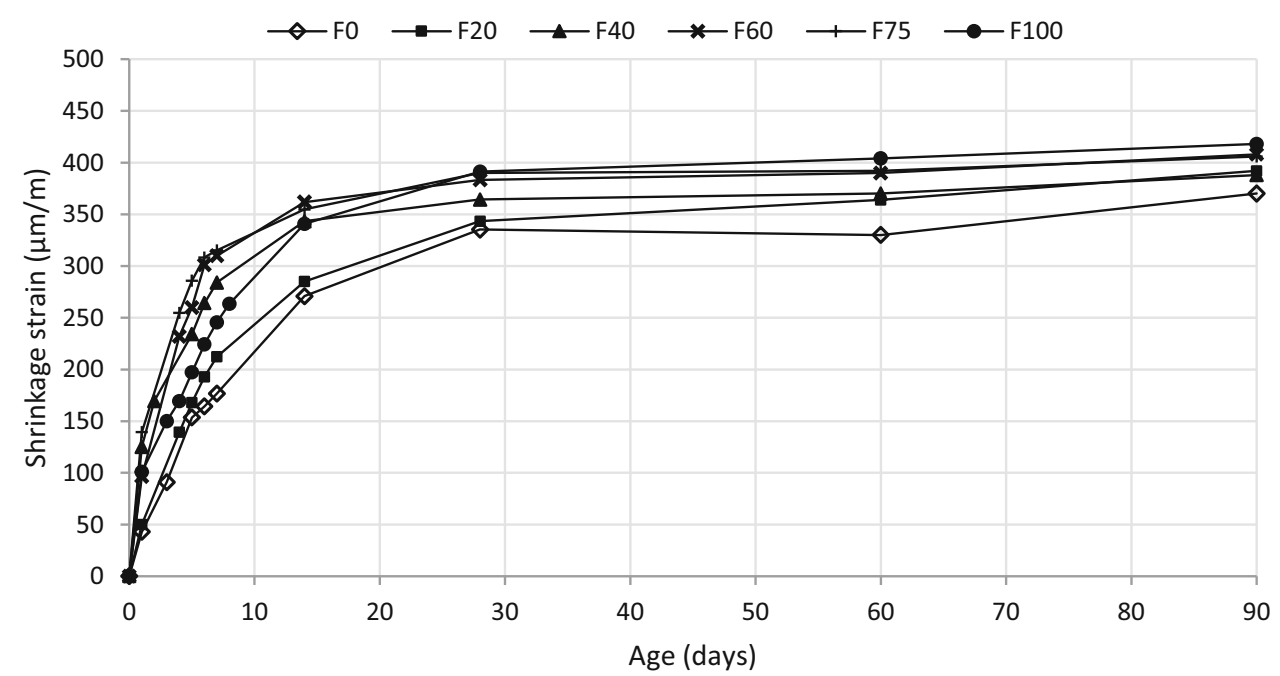

Fig. 9 Shrinkage strain as a function of age for all mixes F0 through F100.

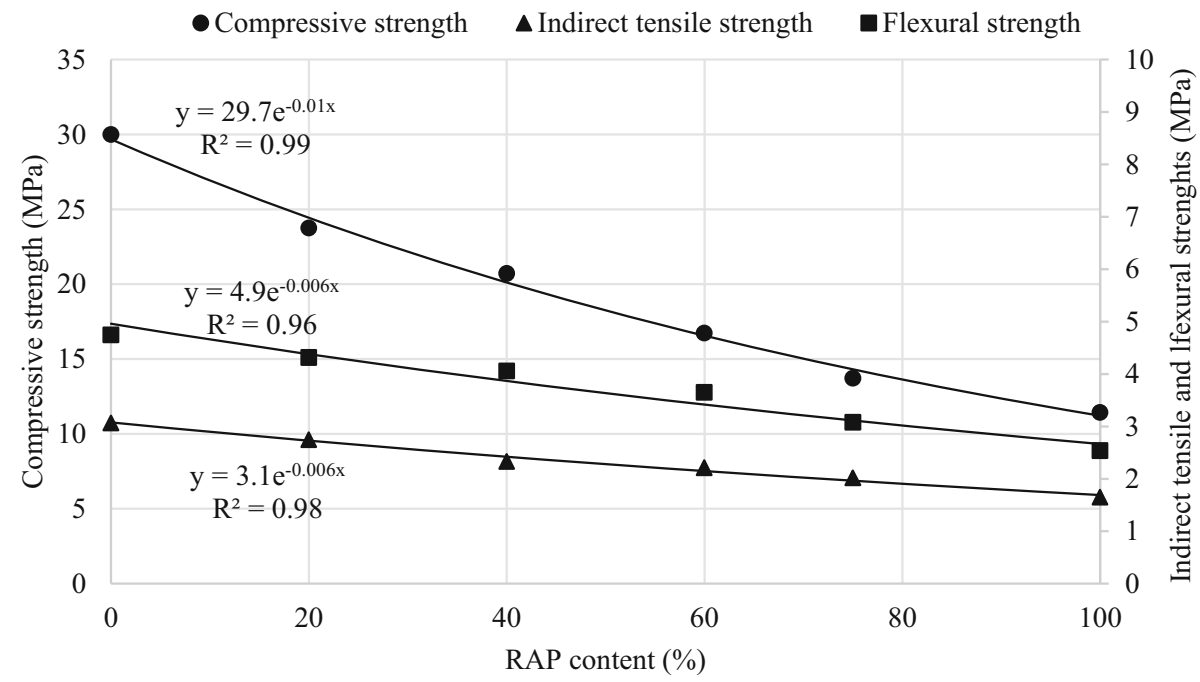

Fig. 10 Variation of compressive, indirect tensile and flexural strengths as a function of RAP content.
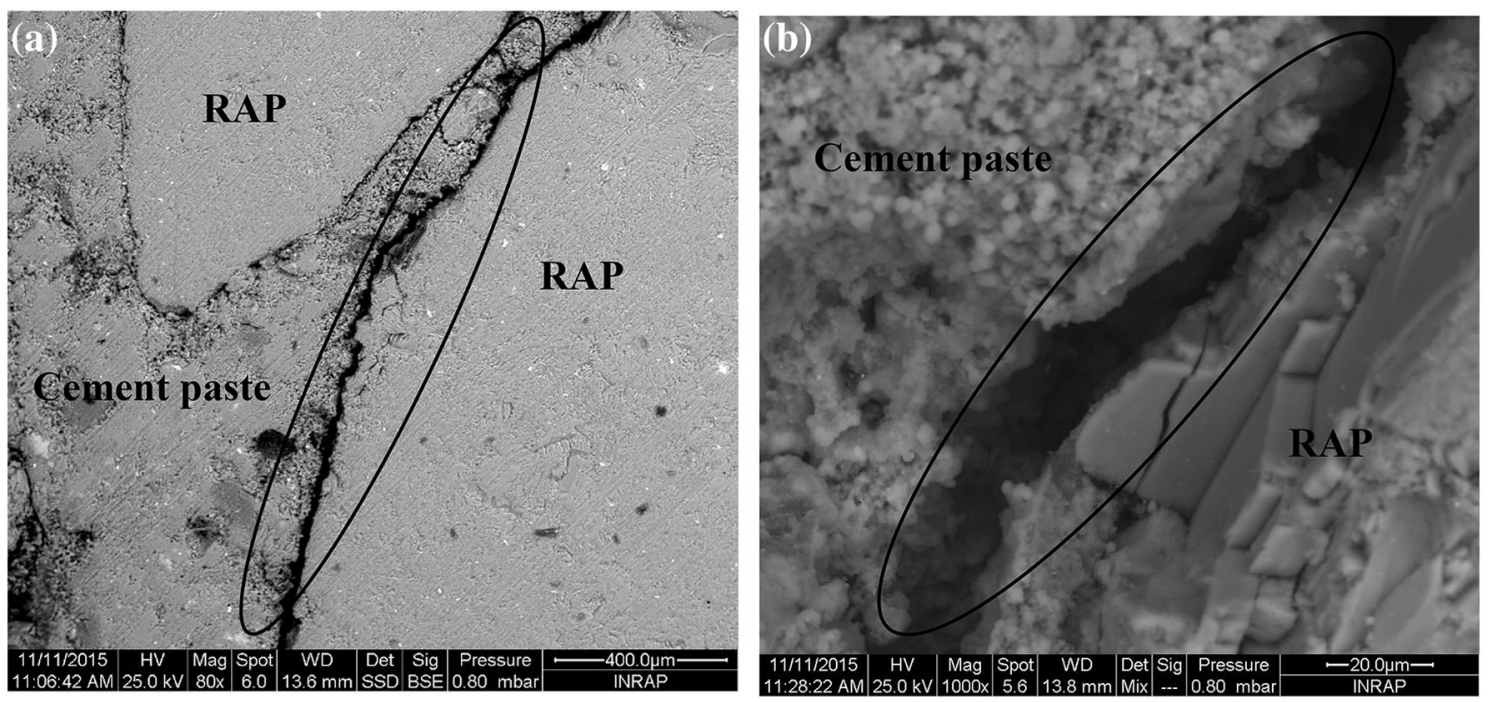

Fig. 11 SEM images from Mix F100—a magnification: $80 \times$, b magnification: $1000 \times$. 
asphalt on the surface of coarse aggregates reduces their roughness and inherent any chemical bonding that might have occurred between the minerals contained in the aggregates and the cement paste. This was confirmed by images obtained from scanning electron microscope (SEM) on mix F100, as shown by Fig. 11. The figure clearly shows the presence of a void at the interface between the cement paste and RAP. Looking at Eqs. 7-9, it is also noted that the rate of decrease in the compressive strength is much higher than that of the indirect tensile and flexural strengths (the exponential component is 0.01 for compressive strength and only 0.006 for indirect and flexural strengths).

As presented (Fig. 8) and discussed earlier, the incorporation of RAP considerably decreases the modulus of elasticity of PCC. This finding is also expected since, as explained by Mehta and Monteiro (1993), the transition zone serves as a bridge between the aggregates and the cement paste. Even if these two later phases have high stiffness, the stiffness of the composite could be low because of the voids and microcracks present in the transition zone which do not permit stress transfer. With PCC incorporating RAP, in addition to the voids and microcracks present in the transition zone, another soft material (asphalt) is added, which will reduce more the stiffness of the composite. This reduction of stiffness is of great importance in rigid pavement design. Indeed, since the modulus of elasticity decreases, the horizontal tensile stress at the bottom of the concrete slab induced by truck loading will decrease if linear elastic properties of materials are used as is the case in all pavement design procedures worldwide. For instance, Fig. 12 presents the calculated horizontal tensile stress at the bottom centre of a concrete slab induced by a standard $65-\mathrm{kN}$ dual tires with a contact pressure of $662 \mathrm{kPa}$, placed at the top centre of the slab. The hypothetical rigid pavement is composed of a 20-cm-thick concrete slab with elastic modulus ranging from 14 to $30 \mathrm{GPa}$, placed on top of a granular base layer with a modulus of $400 \mathrm{MPa}$, placed on top of a subgrade with a modulus of $100 \mathrm{MPa}$. The horizontal tensile stress at the bottom of the slab induced from the considered truck loading (no moisture or temperature differential in the concrete slab were considered in this example), which is a critical design variable in rigid pavements, decreases from 1.5 to $1.2 \mathrm{MPa}$,

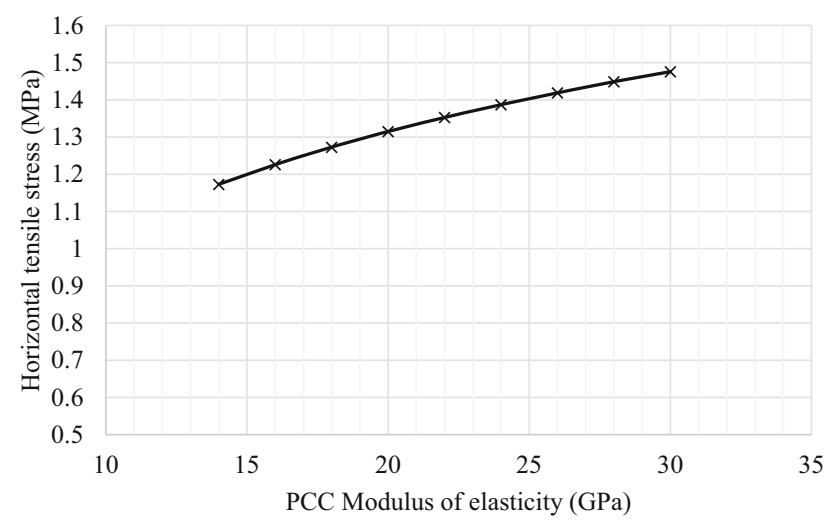

Fig. 12 Calculated horizontal tensile stress at the bottom of concrete slab as a function of modulus of elasticity. when the modulus decreases from 30 to $14 \mathrm{GPa}$. The example is shown to illustrate that reducing the concrete modulus would decrease the flexural stress in the concrete slab. Only a load in the center was used for the example, but the main result (decrease in stress with a decrease in concrete modulus) would be obtained for other load locations (corner or edge). This decrease in the calculated horizontal stress at the bottom of the slab comes to compensate for the decrease in the flexural strength of PCC incorporating RAP.

In terms of shrinkage behaviour (Fig. 9), PCC containing RAP does not differ from that without it. To confirm this finding statistically, an analysis of variance (ANOVA) was performed on the results of the 90-day shrinkage strain for all mixes. The obtained $p$ value of 0.27 indicates that there is no statistical evidence that the mean 90-day shrinkage strain is different between the tested PCC mixes at a level of significance of 0.95 . Since shrinkage is mainly a paste property and the paste volume is similar for all eight tested concrete mixes (same cement content and same w/c ratio), the main shrinkage behaviour is expected to be similar for all the mixes. However, in concrete, the aggregates have a restraining effect on the shrinkage that takes place within the hydrated cement paste. Since RAP has lower modulus than quarried new aggregates, concrete mixes made with RAP are expected to exhibit slightly more shrinkage strain. This is exactly what was found, but the increase in the shrinkage strain (a maximum of $13 \%$ between F0 and F100) was found statistically insignificant.

The strength and shrinkage results lead to conclude that as much as $40 \%$ of RAP could be incorporated into the formulation of PCC (mix F40) and achieve properties that are acceptable for the construction of rigid pavements. This mix was retained to evaluate which portion of RAP (fine or coarse) has more negative effects on PCC mechanical properties as presented in the next section.

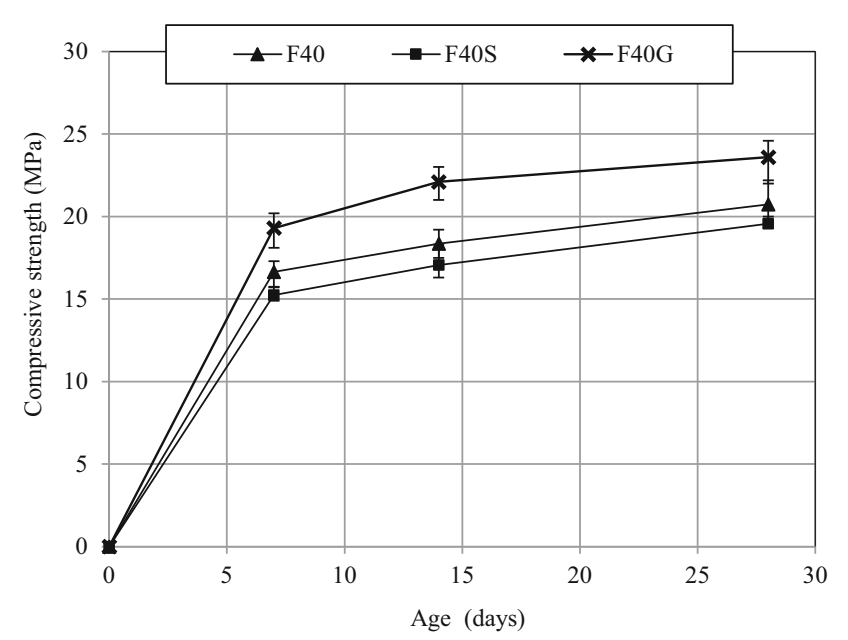

Fig. 13 Compressive strength as a function of age for mixes F40, F40S, and F40G. 


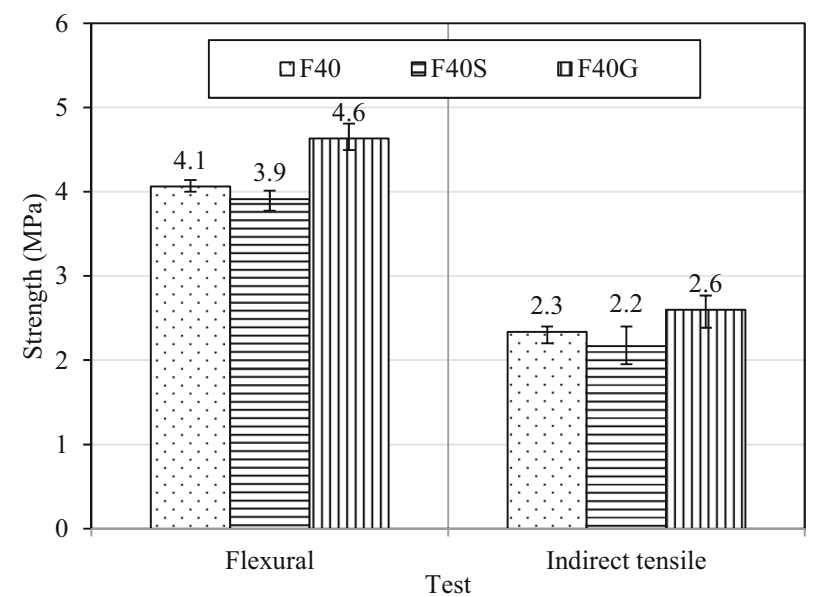

Fig. 14 Indirect tensile and flexural strengths of mixes F40, F40S, and F40G.

\section{Effects of RAP Gradation (Fine or Coarse) on PCC Properties}

In order to evaluate the effect of RAP gradation (fine or coarse) on PCC properties, two additional mixes were formulated based on mix F40. RAP (graded as 0/20) was carefully sieved over a $4 \mathrm{~mm}$ sieve to make two piles of $0 / 4$ and 4/20 graded RAP materials. As shown by Table 2, Mix F40S was proportioned using only 0/4 RAP, while mix F40G was proportioned using only 4/20 RAP. The same mass quantity of RAP was used for all three mixes (F40, F40S, and F40G) to be able to compare between them.

Figure 13 shows the average compressive strength after 7 , 14, and 28 days of age for the three studied mixes. At all ages, mix F40G had the highest compressive strength followed by mix F40, then mix F40S. For instance, after 28 days of age, mix F40S achieved an average of only 19.5 MPa while mix F40G achieved an average of 23.6 $\mathrm{MPa}$, which is about $21 \%$ higher than mix F40S. The same trend was observed for the indirect tensile and flexural strengths (Fig. 14). On the other hand, no differences were

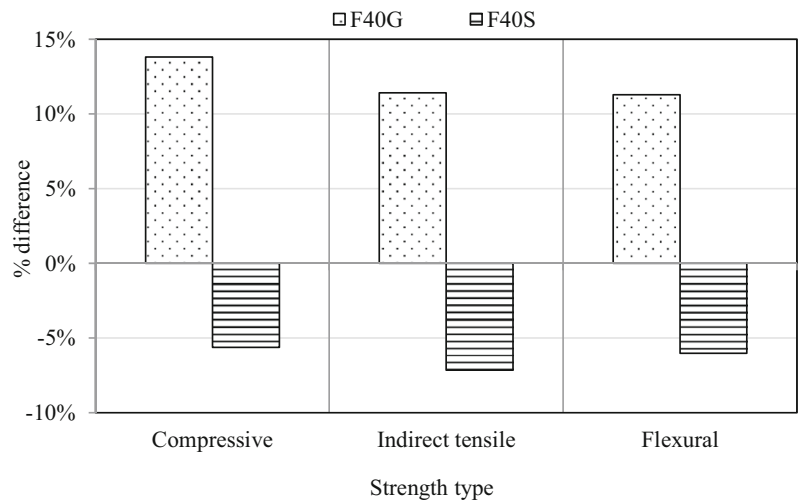

Fig. 16 Percentage difference in compressive, indirect tensile and flexural strength values of mixes F40S and F40G with respect to mix F40.

found in the calculated modulus of elasticity between the three mixes. Figure 15 shows the shrinkage strain development over time for the three studied mixes. The three curves are very similar with a difference after 90 days of age not exceeding $5 \%$.

Figure 16 shows the percentage difference in compressive, indirect tensile, and flexural strength for mixes F40S and F40G with respect to those obtained for mix F40. The figure shows that replacing only the coarse aggregate by its equivalent RAP would have better effects than replacing both coarse and fine aggregates with their corresponding RAP material. For instance, an increase by $14 \%$ is achieved for the compressive strength and by $11 \%$ for the indirect tensile and flexural strengths. On the other hand, replacing just the fine aggregate by RAP would have worse effects than replacing both coarse and fine aggregates with their corresponding RAP material (a decrease of about 6 to $7 \%$ in the mechanical resistance properties). These results could be explained by the fact that the surface area of fine RAP coated with asphalt is higher than that of coarse RAP which leads to an increase in the weakest links represented by the transition zones.

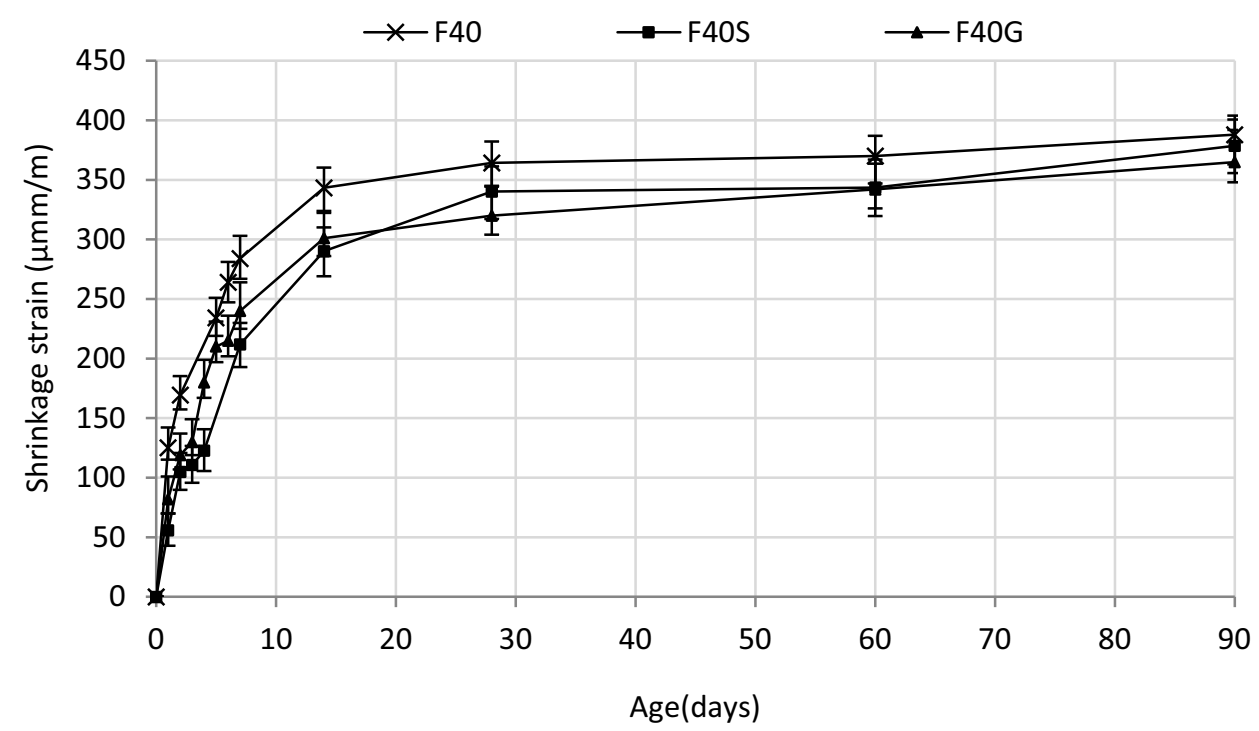

Fig. 15 Shrinkage strain as a function of age for mixes F40, F40S, and F40G. 


\section{Summary and Conclusions}

In a context of sustainable development, using RAP, considered as waste in many countries around the world, in the formulation of PCC reduces the use of natural aggregate resources. For that reason, an experimental laboratory study was performed on several PCC mixes incorporating different percentages of RAP to determine their mechanical behaviour. The results of the various performed tests lead to the following conclusions:

- Asphalt, coated on RAP, does not affect portland cement hydration process.

- An increase in RAP content is associated with a decrease in PCC mechanical properties due to the fact that asphalt present in RAP negatively affects the strength of the PCC interfacial zones.

- The negative effect of RAP is more pronounced for compressive strength than for indirect-tensile and flexural strengths. In fact, the interfacial zones are already weak in tension than in compression and therefore the asphalt negative effect is more perceptible in compression.

- An incorporation of up to 40\% RAP will produce PCC with good quality to be used for constructing rigid pavements. No extra thickness for the concrete slab is needed since the modulus of elasticity of PCC incorporating RAP decreases leading to smaller induced tensile stresses at the bottom of the slab, which compensates for the reduced flexural strength.

- RAP in PCC does not affect its shrinkage behaviour

- For the same RAP content, replacing only the fine portion of aggregates with its equivalent RAP has more negative effects than replacing both fine and coarse or only the coarse portion of aggregates.

\section{Open Access}

This article is distributed under the terms of the Creative Commons Attribution 4.0 International License (http:// creativecommons.org/licenses/by/4.0/), which permits un restricted use, distribution, and reproduction in any medium, provided you give appropriate credit to the original author(s) and the source, provide a link to the Creative Commons license, and indicate if changes were made.

\section{References}

Abdel-Mohti, A., Shen, H., \& Khodair, Y. (2016). Characteristics of self-consolidating concrete with RAP and SCM. Construction and Building Materials, 102, 564-573.

AFNOR. (1992). Chaussées en béton de ciment, exécution et contrôle, NFP 98-170.

Al-Oraimi, S., Hassan, H. F., \& Hago, A. (2009). Recycling of reclaimed asphalt pavement in portland cement concrete. The Journal of Engineering Research, 6(1), 37-45.
Ben Othmen, R., El Euch Khay, S., Louizi, A., \& Neji, J. (2013). Compacted-sand concrete for pavement- tests show suitability of sea-dredged materials aggregate. Concrete International, 35(1), 34-38.

Bermel, B N. (2011). Feasibility of reclaimed asphalt pavement as aggregate in portland cement concrete pavement. Master of Science Thesis, Montana State University, Bozeman, Montana

Brand, R., Al-Qadi, S. (2012). Fractionated reclaimed asphalt pavement (FRAP) as a coarse aggregate replacement in a ternary blended concrete pavement. Illinois Center for Transportation Research Report ICT-12-008

Briaut, M., Nahas, G., Benboudjema, F., \& Torrenti, J. M. (2010). Numerical simulations of the QAB and Langavant semi-adiabatic tests: Analysis and comparison with an experimental measurement campaign. Bulletin des Laboratoires des Ponts et Chaussées, 278, 5-18.

Brito, J., \& Saikia, N. (2013). Recycled aggregate in concrete: Use of industrial, construction and demolition waste. London: Springer.

Calkins, M. (2009). Materials for sustainable sites: A complete guide to the evaluation, selection, and use of Sustainable Construction Materials. Hoboken, NJ: Wiley.

Choi, H., Choi, H., Lim, M., et al. (2016). Evaluation on the mechanical performance of low-quality recycled aggregate through interface enhancement between cement matrix and coarse aggregate by surface modification technology. International Journal of Concrete Structures and Materials, 10, 87-97.

De Larrard, F. (1999). Concrete mixture- proportioning- a scientific approach. Modern Concrete Technology Series, No 9, E \& FN SPON, London.

Delwar, M., Fahmy, M., \& Taha, R. (1997). Use of reclaimed asphalt pavement as an aggregate in portland cement concrete. ACI Materials Journal, 94(3), 251-256.

El Euch Khay. S., El Euch Ben Saïd, S., Loulizi, A., Néji, J., (2014). Laboratory investigation of cement-treated reclaimed asphalt pavement materiel. ASCE, Journal of Materials in Civil Engineering.

El Euch Khay, S., Neji, J., \& Loulizi, A. (2010a). Shrinkage properties of compacted sand concrete used in pavements. Construction and Building Materials, 24, 1790-1795.

El Euch Khay, S., Neji, J., \& Loulizi, A. (2010b). Compacted sand concrete in pavement construction: An economical and environmental solution. ACI Materials Journal, 107(2), 195-202.

El Euch Khay, S., Neji, J., \& Loulizi, A. (2011). Compacted dune sand concrete for pavement applications. Proceedings of the ICE-Construction Materials, 164(2), 87-93.

Hassan, K. E., Brooks, J. J., Erdman, M. (2000). The use of reclaimed asphalt pavement (RAP) aggregates in concrete. In Waste materials in construction, waste management series (Vol. 1, pp. 121-128). Elsevier Science: Oxford.

Hossiney, N., Tia, M., \& Bergin, M. J. (2010a). Concrete containing RAP for use in concrete pavement. International Journal of Pavement Research and Technology, 3(5), $251-259$ 
Hossiney, N., Tia, M., Bergin, M. J. (2010). Concrete containing RAP for use in concrete pavement. International Conference on Sustainable Concrete Pavements, Sacramento, California.

Huang, B., Shu, X., \& Burdette, E. G. (2006). Mechanical properties of concrete containing recycled asphalt pavements. Magazine of Concrete Research, 58(5), 313-320.

INORPI. Ciment. (1996): Composition, Spécification et Critères de Conformité. NT47-01.

Kolias, S. (1996). Mechanical properties of cement-treated mixtures of milled bituminous concrete and crushed aggregates. Materials and Structures, 29, 411-417.

Li, G., Zhao, Y., Pang, S. S., \& Huang, W. (1998). Experimental study of cement-asphalt emulsion composite. Cement and Concrete Research, 28(5), 635-641.

Mahmoud, E., Ibrahim, A., El-Chabib, H., et al. (2013). Consolidating concrete incorporating high volume of fly ash, slag, and recycled asphalt pavement. International Journal of Concrete Structures and Materials, 7, 155-163.

Mathias, V., Sedran, T.F., De Larrard, F., (2004). Recycling reclaimed asphalt pavement in concrete roads. International RILEM Conference on the Use of Recycled Materials in Buildings and Structures, Barcelona, Spain

McNeil, K., \& Kang, T. H. K. (2013). Recycled concrete aggregates: A review. International Journal of Concrete Structures and Materials, 7, 61-69.
Mehta, P. K., \& Monteiro, P. J. M. (1993). Concrete: Structure, properties, and materials (2nd ed.). Englewood Cliffs, NJ: Prentice Hall.

Okafor, F. O. (2010). Performance of recycled asphalt pavement as coarse aggregate in concrete. Leonardo Electronic Journal of Practices and Technologies, 17, 47-58.

Roberts, F. L., Kanddhal, P. S., Brown, E. R., Lee, D. Y., \& Kennedy, T. W. (1996). Hot-mix asphalt: Materials, mixture, design, and construction (2nd ed.). Lanham, MD: NAPA Education Foundation.

Sommer, H. (1994). Recycling of concrete for the reconstruction of the concrete pavement of the motorway ViennaSalzburg. In 7th international concrete roads symposium, Vienna, Austria

Topcu, I. B., \& Isikdag, B. (2009). Effects of crushed RAP on free and restrained shrinkage of mortars. International Journal of Concrete Structures and Materials, 3(2), 91-95.

Yehia, S., Helal, K., Abusharkh, A., et al. (2015). Strength and durability evaluation of recycled aggregate concrete. International Journal of Concrete Structures and Materials, 9, 219-239.

Ulm, F., \& Coussy, O. (1994). Coupling in early-age concrete: From material modelling to structural design. International Journal of Solids and Structures, 35(31-32), 4295-4311.

Waller, V. (2000). Relation entre composition des bétons, exothermie en cours de prise et résistance en compression, collection études et recherches des laboratoires des ponts et chaussées, série ouvrages d'art :OA35-LCPC, France. 